\title{
Coenzyme Q10 Concentrations in Perennial Rye Grass and White Clover
}

\author{
Desmond P Leadon ${ }^{1 *}$, Kazunori Hosoe ${ }^{2}$, S Clare Guy ${ }^{3}$ and Warwick M Bayly ${ }^{4}$ \\ ${ }^{1}$ The Irish Equine Centre, Johnstown, Naas, Co Kildare, Ireland \\ ${ }^{2}$ Supplemental Nutrition Division, Kaneka Corporation, Japan \\ ${ }^{3}$ Teagasc, Animal and Grassland Research and Innovation Centre, Ireland \\ ${ }^{4}$ Department of Veterinary Clinical Sciences, College of Veterinary Medicine, USA
}

*Corresponding author: Desmond P Leadon, The Irish Equine Centre, Johnstown, Naas, Co Kildare, Ireland.

Received Date: January 20, 2020

Published Date: January 23, 2020

\section{Introduction}

Coenzyme Q10 (CoQ10) is an essential, naturally occurring fat soluble vitamin-like lipid that is found in virtually all tissues of the body as either ubiquinol-10 which is the reduced, bioactive form ( $95 \%$ of plasma CoQ10), or ubiquinone-10 (oxidized CoQ10) [13]. Coenzyme Q10 is the predominant coenzyme $Q$ homologue in livestock, while CoQ9 is the predominant form of coenzyme $Q$ in mice and rats [4]. Tissue concentrations of CoQ10 are a function of its endogenous synthesis and the gastrointestinal absorption of ubiquinol from dietary sources of CoQ10. Coenzyme Q10 is essential for mitochondrial oxidative phosphorylation and, thus, aerobic production of adenosine triphosphate. Consequently, CoQ10 is found in highest concentrations in tissues with high metabolic rates, such as myocardium, liver, kidney, and skeletal muscle [1]. Adenosine triphosphate synthesis also is associated with the production of large amounts of reactive oxygen species (ROS; eg, superoxide and hydroxyl radicals) which are a major source of oxidative stress in the mitochondria. Ubiquinol-10 is the only endogenously synthesized antioxidant lipid in the body [5] and, as such, serves as a potent scavenger of ROS and acts as the first line of defence against mitochondrial oxidative stress. CoQ10 concentrations often decrease and/or become depleted before other antioxidants like $\alpha$ - and $\gamma$-tocopherol are affected, as the concentrations of these antioxidants and vitamin $\mathrm{C}$ are often regenerated or maintained at the expense of ubiquinol-10 $[3,5,6]$. Clinical CoQ10 deficiencies that respond to increased intake of CoQ10, usually as a dietary supplement, have been recognized in people with muscle weakness and increased susceptibility to oxidative stress [7-9].
Cereal grains are virtually devoid of CoQ10 [10]. However, the CoQ10 content of pasture grasses is uncertain. Because of this and, as ruminants and horses are naturally herbivorous, grazing as many as 17 hours/day [11], we quantitated the ubiquinol-10 and ubiquinone-10 contents of both a popular European pasture grass and a widespread pasture legume to develop a clearer sense of the daily intake of CoQ10 by grazing herbivores. This information was particularly relevant for horses which, in contrast to ruminants that can produce CoQ10 from ruminal fermentation processes, are monogastric herbivores and thus heavily reliant on dietary intake of CoQ10 for the maintenance of tissue CoQ10 concentrations.

Herbage samples (five samples of perennial ryegrass; two samples of white clover) were obtained from four paddocks at the Teagasc, Animal and Grassland Research and Innovation Centre, Moorepark, Fermoy, Co. Cork, Ireland (50 ${ }^{\circ} 09^{\prime} \mathrm{N}$; $8{ }^{\circ} 16^{\prime} \mathrm{W}$ ). The soil type was a free-draining acid brown earth of sandy loam-toloam texture. In 2010, the paddocks (average size $1.0 \mathrm{ha}$ ) were sown with perennial ryegrass cultivars $(37 \mathrm{~kg} / \mathrm{ha}$; a 50:50 mixture of Astonenergy and Tyrella) and white clover (5kg/ha; a 50:50 mixture of medium leaved white clover cultivars, Chieftain and Crusader). Soil analysis indicated that all four paddocks had a similar $\mathrm{pH}$ (6.5) and nutrient status (6.5-10 mg/L for phosphorus and $140 \mathrm{mg} / \mathrm{L}$ for potassium). The $\mathrm{pH}$ and nutrient status of the soils were considered representative of temperate climate grassland production [12]. The herbage samples were collected by taking 15 samples in a ' $W$ ' formation across each paddock. These samples were taken at $4 \mathrm{~cm}$ above ground level using a Gardena (Accu 60, Gardena International GmbH, Ulm, Germany) hand shears. Each 
herbage sample (100g per sample) was separated into perennial ryegrass (and other grass species) and white clover components. These herbage sub-samples were freeze dried and milled through a $1 \mathrm{~mm}$ sieve. Concentrations of ubiquinol-10 and ubiquinone-10 in the pasture samples were determined using the LC/MS/MS method described by Ruiz Jimenez et al. [13] with a minor modification. Calibration curves were derived from the peak area ratios (analyte/ internal standard) using weighted linear least-squares regression of the peak area ratio versus the concentration of the standards. The limits of detection of ubiquinol-10 and ubiquinone-10 were both $0.08 \mu \mathrm{g} / \mathrm{g}$ and their limits of quantification were both $0.25 \mu \mathrm{g} / \mathrm{g}$. Ubiquinol-10 and ubiquinone-10 concentrations were summed to determine total CoQ10 concentration.

Results are shown in Table 1. Total CoQ10 content ranged from a high value of $3.34 \mu \mathrm{g} / \mathrm{g}$ in one white clover sample to a low of 0.19 $\mu \mathrm{g} / \mathrm{g}$ in one of the PR samples and was higher overall in white clover (3.1 \pm 0.3 vs $0.2 \pm 0.05 \mu \mathrm{g} / \mathrm{g} ; \mathrm{P}<0.001)$. Ubiquinone- 10 content was greater in white clover $(3.0 \pm 0.3$ vs $0.2 \pm 0.05 \mu \mathrm{g} / \mathrm{g} ; \mathrm{P}<0.001)$ and above the limits of detection in all white clover and PR samples, ranging from a high of $3.22 \mu \mathrm{g} / \mathrm{g}$ in white clover to the lowest value of $0.19 \mu \mathrm{g} / \mathrm{g}$ which was seen in a PR sample. Ubiquinol-10 levels were detected in all clover samples, but not in all PR samples $(<0.08$ $\mu \mathrm{g} / \mathrm{g}$ ).

Table 1: Concentrations of ubiquinol-10, ubiquinone-10 and total CoQ10 in 7 perennial ryegrass (PR) and 2 white clover (WC) samples.

\begin{tabular}{|c|c|c|c|}
\hline Sample & $\begin{array}{c}\text { Ubiquinol-10, } \\
\boldsymbol{\mu g} / \mathbf{g}\end{array}$ & $\begin{array}{c}\text { Ubiquinone-10, } \\
\boldsymbol{\mu g} / \mathbf{g}\end{array}$ & $\begin{array}{c}\text { Total CoQ10, } \\
\boldsymbol{\mu g} / \mathbf{g}\end{array}$ \\
\hline WC1 & 0.11 & 2.77 & 2.89 \\
\hline WC2 & 0.12 & 3.22 & 3.34 \\
\hline Mean \pm SD & & $3.0 \pm 0.3^{*}$ & $3.1 \pm 0.3^{*}$ \\
\hline PR1 & $<0.08$ & 0.33 & 0.33 \\
\hline PR2 & $<0.08$ & 0.21 & 0.21 \\
\hline PR3 & $<0.08$ & 0.21 & 0.21 \\
\hline PR4 & $<0.08$ & 0.21 & 0.21 \\
\hline PR5 & $<0.08$ & 0.21 & 0.21 \\
\hline PR6 & $<0.08$ & 0.21 & 0.21 \\
\hline PR7 & $<0.08$ & 0.19 & 0.19 \\
\hline Mean \pm SD & & $0.2 \pm 0.05$ & $0.2 \pm 0.05$ \\
\hline
\end{tabular}

$\mathrm{SD}=$ standard deviation. ${ }^{*}$ denotes a significant difference between least square means for white clover and perennial rye grass $(p<0.001)$.

To our knowledge, this is the first documentation of the ubiquinol-10 and ubiquinone-10 concentrations of commonly grazed pasture elements. Our findings indicated that both forms of CoQ10 could be found in white clover and PR and, as such, represented normal feed constituents for horses and other herbivores. Further studies to measure CoQ10 concentrations in other herbages and to evaluate the extent to which pasture CoQ10 concentrations vary in time and location are needed. Regardless, however, it could be reasonably expected that one constant in the natural herbivorous equine diet is that there is regular and predictable daily ingestion of CoQ10.
Ubiquinol-10 was detectable in some, but not all, PR samples. Failure to identify ubiquinol-10 did not mean that there was no ubiquinol-10 in these samples. Oxidation of ubiquinol-10 to ubiquinone-10 in the period between sampling at the farms and freeze drying at the laboratory in Ireland may have occurred, as such reactions are rapid when ubiquinol-10 is exposed to air. Another possibility stems from difficulty identifying the chromatographic ubiquinol peak from noise peaks in the LC/MS/MS chromatograms for PR samples.

In conclusion, both a widespread European pasture grass (PR) and similarly popular legume (WC) contained CoQ10. Consequently, it was concluded that CoQ10 is a normal feed constituent of grazing herbivores and, in situations where food or fibre producing livestock, or horses, are housed indoors for long periods, supplementation of their diets with CoQ10 might be indicated.

\section{Acknowledgement}

None.

\section{Conflict of Interest}

No conflict of interest.

\section{References}

1. Bhagavan HN, Chopra RK (2006) Coenzyme Q10: absorption, tissue uptake, metabolism and pharmacokinetics. Free Rad Res 40(5): 445453.

2. M Turunen, J Olsson, G Dallner (2004) Metabolism and function of coenzyme Q Biochim Biophys Acta 1660(1-2): 171-199.

3. Crane FL (2001) Biochemical functions of coenzyme Q10. J Am Coll Nutr $20(6): 591-598$.

4. Ramasarma T (1985) Natural occurrence and distribution of coenzyme Q. In: Lenaz G, (edr), Coenzyme Q: biochemistry, bioenergetics and clinical applications of ubiquinone. John Wiley \& Sons Ltd, USA, pp. 6781.

5. Bentiger M, Brismar K, Dallner G (2007) The antioxidant role of coenzyme Q. Mitochondrion 7S: S41-S50.

6. Niki E (1997) Mechanisms and dynamics of antioxidant action of ubiquinol. Molec Aspects Med 18: S63-70.

7. Miles MV, Miles L, Tang PH, Horn PS, Steele PE, et al. (2008) Systematic evaluation of muscle coenzyme Q10 content in children with mitochondrial respiratory chain enzyme deficiencies. Mitochondrion 8(2): 170-180.

8. Rahman S, Hargreaves I, Clayton P, Heale S (2001) Neonatal presentation of coenzyme Q10 deficiency. J Pediatr 139(3): 456-458.

9. Yubero D, Montero R, Artuch R, Land JM, Heales SJR, et al. (2014) Biochemical diagnosis of coenzyme Q10 deficiency. Mol Syndromol 5(34): 147-155.

10. Kamei M, Fujita T, Kanbe T, Sasaki K, Oshiba K, et al. (1986) The distribution and content of ubiquinone in foods. Int J Vitam Nutr Res 56(1): 57-63.

11. Mayes E, Duncan P (1986) Temporal patterns of feeding behavior in free-ranging horses. Behaviour 96: 105-129.

12. Coulter BS, Lalor S (2008) Major and micronutrient advice for productive agricultural crops, ( $3^{\text {rd }}$ edn). Teagasc, Oak Park, Co Carlow, Europe.

13. Ruiz Jimenez J, Priego Capote F, Mata Granados JM, Quesada M, Luque de Castro MD (2007) Determination of the ubiquinol-10 and ubiquinone-10 (coenzyme Q10) in human serum by liquid chromatography tandem mass spectrometry to evaluate the oxidative stress. J Chromatog A 1175(2): 242-248. 